\title{
Fatores de risco e de proteção evidenciados em idosos de Ivoti-RS: intervenções psicossociais na área da Gerontologia ${ }^{1}$
}

\author{
Raquel Maria Rossi Wosiack*, Cynthia Schwarcz Berlim", Geraldine Alves dos Santos"**
}

\section{Resumo}

Este artigo objetiva realizar um levantamento dos fatores de risco e de proteção, evidenciados em idosos moradores da cidade de Ivoti -RS, buscando incrementar intervenções psicológicas para essa faixa etária. Participaram deste estudo 15 idosos, entre os quais, 14 mulheres e um homem, ambos atendidos em grupo e individualmente pelo projeto de Psicogerontologia da Universidade Feevale. As idades variaram entre 58 e 82 anos. O referencial teórico foi baseado no modelo que integra o envelhecimento e o desenvolvimento humano como um processo contínuo de Paul Baltes, o que se assemelha ao modelo de resiliência que promove, positivamente, o potencial humano. A metodologia utilizada foi qualitativa, com abordagem fenomenológica, a qual permite, por meio da história de vida relatada em sessões in- dividuais e grupais, que sejam percebidos os fatores de risco e os fatores protetivos vividos pelos participantes. Constatou-se que o trabalho de acompanhamento realizado, incluindo a escuta e a orientação do idoso pode ser um dos caminhos para que o processo de desenvolvimento da resiliência ocorra. Conclui-se, ainda, que as intervenções psicossociais necessitam ser sistemáticas para que possam contribuir para o autodesenvolvimento individual e grupal, bem como reforcem o sistema a autoajuda e diminuam o isolamento dos idosos.

Palavras-chave: Envelhecimento. Fatores de risco. Fatores de proteção. Resiliência. História de vida.

* Psicóloga, Arteterapeuta, doutoranda em Ciências da Atividade Física e do Desporte, pela Universidade de Cádiz, Espanha. Mestre em Educação pela Universidade Federal do Rio Grande do Sul, Pós-Graduada em Arteterapia, Coordenadora e Professora de Arteterapia no curso de Pós-Graduação e em Psicologia da Universidade Feevale. Professora convidada nos cursos de Pós-Graduação em Arteterapia da Universidade de Caxias do Sul (UCS) e da Universidade de Passo Fundo (UPF). E-mail: raquelrossi@feevale.br.

** Psicóloga, Especialista em Psicologia Jurídica. Mestre em Psicologia Social e da Personalidade. Professora do curso de Psicologia e Extensionista do Centro Integrado de Psicologia da Universidade Feevale. E-mail: berlim@feevale.br.

*** Psicóloga, Especialista em Gerontologia Social. Mestre em Psicologia Clínica, Doutora em Psicologia, Pós-Doutora na Faculdade de Serviço Social da PUCRS. Professora Titular da Universidade Feevale no curso de Psicologia e no Mestrado em Inclusão Social e Acessibilidade. Diretora técnico-científica da ANG-RS e Pesquisadora responsável pelo Estudo da Fragilidade em Idosos Brasileiros - Rede Fibra no município de Ivoti. E-mail: geraldinesantos@feevale.br.

$\rightarrow$ http://dx.doi.org/10.5335/rbceh.2013.2495 


\section{Introdução}

O tema resiliência é considerado um desafio para alguns estudiosos, porém ainda mostra-se desconhecido para outros. Os dois temas, envelhecimento e resiliência requerem investigações que levem em consideração, sobretudo, a nossa realidade. Além disso, são poucas as publicações e pesquisas que relacionam esses dois temas.

O envelhecimento humano é entendido, neste estudo, como um fenômeno que se insere em um processo de desenvolvimento, de crescimento, de aprendizagem, de amadurecimento e de aperfeiçoamento humano (COUTO, 2007). Por isso, o idoso precisa de atitudes positivas em sua vida, as quais podem ser desenvolvidas durante $o$ aprendizado de viver consigo mesmo, reconhecendo seus fatores de risco e também os que o levam a uma qualidade de vida significativa. Assim, os idosos poderão ampliar a compreensão de si, percebendo suas qualidades, respeitando seus limites, aceitando-se como ser humano e reencontrando-se, reforçando suas forças interiores e visualizando uma nova esperança de vida.

Dessa forma, este estudo orienta-se a partir do seguinte problema: quais os fatores de risco e os de resiliência, existentes na vida dos idosos estudados, que os auxiliariam a superar ou não suas dificuldades?

Nesse sentido, torna-se importante para os municípios, para os serviços de saúde e para as políticas públicas voltadas para a saúde dos idosos, que sejam desenvolvidos grupos para auxiliar na promoção da qualidade de vida e do bem-estar desses indivíduos.

\section{Processo de envelhecimento}

Considerar a velhice como a idade de declínio mental e corporal, como o momento da involução dos sentidos e das funções vitais, é adotar uma visão restrita do processo de envelhecimento. A Gerontologia não compreende a velhice somente do ponto de vista biológico, mas, principalmente, com base em uma ótica social e existencial. Segundo Souza (2005, p. 36), "Todo ser humano envelhece; o que difere é o modo de chegar à Terceira Idade. Envelhecer satisfatoriamente depende do delicado equilíbrio entre as limitações e as potencialidades do indivíduo".

A subjetividade humana tem sido pouco considerada e o sujeito violentado na sua trajetória do envelhecer, quando por meio da tecnologia médica volta-se muito para as afecções de ordem orgânica. O resultado dessa situação são sintomas depressivos, observados em muitos idosos. Segundo Barros (1998), além das alterações no corpo, o envelhecimento traz ao ser humano uma série de mudanças psicológicas, que podem resultar em resistências a novos papéis, em falta de motivação, em dificuldades de planejar o futuro, em distorções de autoimagem e autoestima, fazendo transparecer uma necessidade de trabalhar as perdas orgânicas, afetivas e sociais.

Assim, Py (2004) recorda que na dimensão subjetiva do corpo humano revela-se o sujeito, que fala de si e que se representa em sua história, nos acontecimentos de sua vida, dando um sentido a sua existência. Nesse sentido, a história pessoal é também uma criação social. $O$ sujeito idoso ao sentir o afastamento do 
padrão do corpo jovem, socialmente instituído, se sente excluído. A reflexão aqui proposta sugere que, embora exista a discriminação da sociedade em relação aos idosos, ainda é possível manter-se ativo, ter sonhos e lutar por seus objetivos.

Compartilhando essa ideia, Erikson (1998) apresenta a velhice como mais um estágio da vida. A crise experimentada pelos idosos pode proporcionar ganhos significativos, especialmente, pela possibilidade de contribuição por meio da troca de experiências vivenciadas no decorrer de sua vida.

Jung (1984) informava que os últimos anos são preciosos para que se faça uma revisão da vida e reparar erros. Nesse sentido, para esse autor, a vivência dessa etapa seria fundamental para o desenvolvimento pleno da personalidade. $\mathrm{O}$ autor considera que:

[...] o ser humano não chegaria aos setenta ou oitenta anos, se esta longevidade não tivesse um significado para a sua espécie. Por isso, a tarde da vida humana deve ser também um significado e uma finalidade próprios, e não pode ser apenas um lastimoso apêndice da manhã da vida (JUNG, 1984, p. 787).

Portanto, conclui-se que é preciso que o indivíduo esteja atento ao estilo de vida que adota para que o organismo mantenha-se em condições saudáveis, propiciando, assim, um envelhecimento com qualidade de vida. Outro aspecto que precisa ser evidenciado é a heterogeneidade do processo de envelhecimento, o qual, portanto, não é suscetível a fórmulas simplistas e padronizadas. As pessoas devem compreender a necessidade de tomarem suas próprias atitudes e a sociedade deve ter flexibilidade para aceitá-las (BALTES, 1993).
O conceito de velhice bem-sucedida está diretamente ligado ao contexto social em que o idoso vive e, também, a sua história de vida. Em relação a esse conceito Neri complementa explicando:

Velhice bem sucedida é assim condição individual e grupal de bem estar físico e social, referenciada aos ideais da sociedade e às condições e aos valores existentes no ambiente em que o indivíduo envelhece, e às circunstâncias de sua história pessoal e de seu grupo etário. Finalmente uma velhice bem sucedida preserva o potencial individual para o desenvolvimento, respeitando os limites da plasticidade de cada um (NERI, 2005, p. 24).

Dentro dessa dinâmica, são necessários ambientes que possibilitem o desenvolvimento das capacidades latentes do idoso, evidenciando aquelas em que ele possa valer-se de seus limites, o que deve ocorrer aliado à utilização de recursos e de tecnologias, a fim de suprir os déficits do processo de envelhecimento. Nesse processo, pode haver um desiquilíbrio entre as perdas e os ganhos, favorecendo o desenvolvimento da resiliência.

\section{Resiliência}

No período da velhice ocorrem muitas mudanças nos âmbitos sociais, biológicos e psicológicos. Porém, além de doenças, de limitações e declínios, também encontram-se aspectos positivos e potencialidades, manifestadas de forma subjetiva entre os idosos. Para favorecer um envelhecimento saudável, é preciso que se promovam fatores protetivos, já que são fortes influenciadores da capacidade de adaptação a fatores de risco. A capacidade de realizar essa adaptação é chamada de resiliência. 
A noção de resiliência foi criada pelas ciências exatas, em especial, a física e a engenharia, as quais a definiram como energia de deformação máxima que um material é capaz de armazenar sem sofrer alterações permanentes. Quando foi adaptada para as ciências humanas e médicas, foram consideradas as complexidades de qualquer estudo voltado aos aspectos emocionais do ser humano (ASSIS; PESCE; AVANCI, 2006). Assim, no que se refere ao ser humano, a resiliência não significa um retorno a um estado anterior, mas a superação ou a adaptação diante de uma dificuldade considerada como risco (FORTES, PORTUGUEZ; ARGIMON, 2009).

Nesse sentido, Rutter (1987) bem como Pesce et al. (2004) concordam que essa definição de resiliência converge para um somatório de processos de natureza social e psíquica que permitem o desenvolvimento sadio mesmo em contextos contrários a isso. Considerando a resiliência como um processo, essa não pode ser considerada como um atributo do sujeito ou uma característica adquirida ao longo do desenvolvimento. A resiliência deve ser considerada como um fenômeno interativo entre o indivíduo e o seu meio. Portanto, é preciso o estudo dos fatores considerados de risco e de proteção, para identificar quais podem levar, ou não, ao desenvolvimento da resiliência.

Carpena e Koller (1999) apresentam alguns elementos capazes de favorecer $o$ desenvolvimento da resiliência, como a família, o bom relacionamento familiar, a competência materna e a capacidade de transmitir valores. Além dos aspectos citados, os autores também referem-se aos chamados fatores protetores ou protetivos que seriam uma espécie de muro de contensão, os quais atuam como moderadores nas situações de risco, uma vez que a existência e a disponibilidade de uma relação de cuidado receptiva e estável no tempo seria o fator mais influente. Essa presença deve estar caracterizada por um contato próximo, estimulador e afetuoso, principalmente, com a criança. Por meio desses fatores, moderadores ou protetores, que se agregam a outras contribuições presentes nas interações, surge o fenômeno da resiliência.

Koller (1999) informa que três fatores de proteção são essenciais ao desenvolvimento: a) características da personalidade: autonomia, autoestima, orientação social positiva; b) harmonia familiar e ausência de conflitos; c) disponibilidade de sistemas externos de apoio que animem e reforcem a capacidade do indivíduo de lidar com as circunstâncias da vida. A autora ressalta, ainda, que a resiliência não é um fenômeno geral, as pessoas não são resilientes todo o tempo. Ser resiliente em uma área, não garante resiliência em outra, já que se trata de um processo muito dinâmico, multifatorial e multidimensional.

Para preservar a saúde mental das pessoas, em geral, é necessário prevenir fatores de risco e fortalecer os fatores protetores. Logo, a presença de situações adversas está relacionada ao conceito de resiliência, já que se trata de uma situação em que a pessoa fica exposta ao estresse, mas é capaz de superar e de encontrar estratégias para lidar com a situação de forma positiva, embora, conservando as marcas da experiência 
vivida em suas lembranças e em seus sentimentos. Assim, a pessoa é capaz de extrair algo bom da experiência, ressignificando a dificuldade vivenciada (PESCE et al., 2004).

Couto (2007, p. 19) ao caracterizar os fatores de risco expõe:

De uma maneira geral, pode-se afirmar que os fatores de risco são fatores de natureza pessoal, social ou ambiental que coadjuvam ou incrementam a probabilidade de os indivíduos virem a padecer de perturbações psicológicas. Os fatores de risco estão assim, associados a eventos negativos, os quais potencializam resultados disfuncionais de ordem física, social e/ou emocional e predispõem os indivíduos a resultados indesejáveis também em termos desenvolvimentais. Assim, considera-se risco todo evento que se configura como obstáculo ao nível individual ou ambiental e que potencializa a vulnerabilidade do indivíduo a resultados desenvolvimentais negativos.

Segundo Rutter (1987), fatores ou situações de risco poderiam ser a pobreza e o empobrecimento, as rupturas familiares, as doenças, as perdas de outros significativos, a violência física e psicológica, a atitude discriminatória e preconceituosa (especialmente em idosos) e os eventos estressantes.

Fatores de risco são, atualmente, entendidos como um processo, por isso, não basta somente identificá-los. É preciso que sejam avaliados os resultados associados ao risco, ao tempo de exposição e ao contexto em que ocorreu. Destarte, a ideia do efeito cumulativo de diversos eventos de risco e do seu grau de adversidade ao longo da vida é defendida, por Pesce et al. (2004), como capaz de gerar efeitos negativos no desenvolvimento. Tal aspecto tem importância ímpar em nosso estudo já que, pela população estudada, há grande chance de a pessoa estar exposta a essa situação de risco por longo tempo. Sabe-se que eventos de vida estressantes são considerados para a grande maioria das pessoas como risco à manutenção da saúde e do bem-estar. Isso também é verdade para os idosos (COUTO, 2007).

$\mathrm{Na}$ pesquisa em questão, a classificação de eventos de vida considerados como estressantes seguem sugestão proposta por Couto (2007). Esses seriam os eventos provenientes de duas fontes: físicas e socioculturais. As fontes físicas são relacionadas a traumas físicos (acidentes de carro, incêndios) condições ambientes adversas (poluição, barulho, etc.). As socioculturais seriam no caso de um divórcio, de uma doença, da perda de emprego.

Sabe-se que idosos, mesmo sob condições de limitações e incapacidades funcionais, podem manter um senso positivo de bem-estar. Segundo Neri (2001), perdas na funcionalidade não são, necessariamente, um impedimento para a continuidade do funcionamento cognitivo emocional. Como qualquer ser humano, o idoso ativa mecanismos compensatórios para lidar com essas perdas.

É importante que com o processo de envelhecimento seja desenvolvida a capacidade de resiliência dos idosos, que possa ser mantido o comportamento de adaptação já que na velhice é maior a probabilidade de ocorrerem eventos desagradáveis relacionados à saúde física, ao bem-estar e à vida de entes queridos. Sabendo-se quais fatores constituem-se em elementos protetores, seremos capazes de estimulá-los, favorecendo o surgimento da resi- 
liência. Estudos dessas transformações demonstram a necessidade de planejar e implementar intervenções psicossociais com essa população.

\section{Intervenções psicossociais na velhice}

No trabalho com idoso, existem diferenciadas modalidades, assim como estratégias de intervenção psicossocial. Neste estudo, vamos abordar o enfoque de intervenção de apoio. A psicoterapia de apoio tem como objetivo principal reforçar as diferentes estruturas do ego do paciente. Segundo Cordioli (1998), a psicoterapia de apoio pode ser utilizada em pacientes que tenha apresentado, previamente, um bom nível de funcionamento desse tipo de intervenção e que estejam passando por crises agudas de qualquer natureza, como doença física, luto ou perdas inerentes ao envelhecimento. Nessa terapia busca-se o alívio dos sintomas, a mudança de comportamento manifesto e as defesas úteis ao paciente devem ser reforçadas. Portanto, para esse mesmo autor, as intervenções em psicoterapia de apoio destinam-se a reforçar as funções do ego, utilizando a influência que o terapeuta exerce por meio da sugestão e do aumento do autoconhecimento, proporcionado pelos atendimentos.

Nos atendimentos que ocorrem em grupos, destacamos os grupos de convivência e os terapêuticos. Os grupos de convivência podem constituir-se também em espaço de acolhimento. Esses trazem uma experiência desenvolvida na Europa, onde os idosos reuniam-se nas universidades para a terceira idade. Nesses locais eram desenvolvidas ati- vidades diversificadas com o intuito de entreter e ocupar o tempo ocioso, muitas vezes oriundo do espaço anteriormente ocupado pelo trabalho formal. Os grupos de convivência, geralmente, são organizados de acordo com suas demandas culturais (ZIMERMAN; OSÓRIO, 1997). Em um grupo terapêutico de apoio o idoso poderá desenvolver um conhecimento da realidade que o cerca, favorecendo uma nova forma de ver a vida. A energia destinada, anteriormente, às atividades profissionais poderá ser canalizada para a criação de novas possibilidades dentro das atividades propostas, oportunizando uma noção mais clara do que é significativo para seu momento de vida.

Porém, deve-se considerar necessário o equilíbrio entre as limitações e as potencialidades do indivíduo idoso, o que ajuda no enfrentamento das inevitáveis perdas decorrentes do envelhecimento. Portanto, na condução de um processo terapêutico com idosos em que são utilizadas atividades expressivas, como é o caso dos grupos que foram desenvolvidos, torna-se importante estimular os sentidos desses mediante à experimentação de diversos materiais e atividades expressivas. Souza concorda e completa dizendo que:

A direção de um trabalho com a população idosa deve, sobretudo, incentivar o encontro com o potencial criador e com as independências física e psicológica. A ciência atual vem apontando este como um meio privilegiado de o idoso obter bem-estar e atividade. Pode-se até dizer que uma das chaves para uma velhice saudável está na harmonia da expressão dos sentimentos e no que o idoso faz para manter em atividade a mente e $o$ corpo $(2005$, p. 36$)$. 
Trabalhar com o processo criativo, pode ser um caminho revelador e inspirador que nos ajuda a entrar em contato com a possibilidade abundante e generosa de acreditar, desafiar, reconstruir, criar e expressar as emoções, sentimentos e imagens que trazemos dentro de nós. Dessa forma, a criatividade constitui-se em um elemento importante dentro do trabalho expressivo, já que é um aspecto inerente a todo ser humano, porém nem sempre evidenciado e trabalhado.

Segundo Zimerman (2000), uma atividade de grupo com idosos adquire relevância, porque pode promover a reconstrução da identidade a qual esteja confusa ou perdida, o resgate de vínculos com familiares, bem como trabalhar sucessivas perdas físicas, mentais, profissionais, afetivas, incluindo as mortes de entes próximos. Durante a realização das atividades do grupo com os idosos, é importante que o profissional seja continente (capaz de conter as angústias e as necessidades dos integrantes e também as suas). Quando um grupo é homogêneo, há um melhor entendimento e uma melhor aceitação por parte dos integrantes, propiciando um maior envolvimento para a solução de seus anseios, de suas angústias e de situações de crises que envolvem o envelhecimento.

O fator terapêutico presente a qualquer tipo de intervenção do psicólogo é proporcionado pela inter-relação que esse profissional conseguir estabelecer com os integrantes do grupo, bem como pelas relações entre os membros do grupo. O profissional deve ser continente, empático, espontâneo e estabelecer uma atmosfera propícia à manifestação dos sentimentos que transitam entre os indivíduos do grupo, criando, assim, um clima adequado que seja proveitoso para todos (OSÓRIO, 2007). A partir do convívio, o próprio grupo torna-se terapêutico e os integrantes valorizam a herança cultural da região, resgatando a experiência de vida de cada um.

\section{Método}

O método adotado foi qualitativo, utilizando-se da pesquisa-intervenção (SZYMANSKI; CURY, 2004) que permite, por meio da história de vida, perceber os fatores de risco e os protetivos vividos pelos participantes. Essa abordagem foi escolhida porque preenche os princípios da epistemologia qualitativa apontados por Rey (2000) de que o conhecimento é uma produção construtivo-interpretativa. $\mathrm{O}$ processo de produção de conhecimento tem um caráter interativo e a significação da singularidade pode ser considerada como nível legítimo da produção de conhecimento.

Participaram deste estudo 14 idosos residentes no município de Ivoti, desses, 13 mulheres e um homem, atendidos em grupo e individualmente pela área da Psicogerontologia do Centro Integrado de Psicologia da Universidade Feevale. A idade dos participantes variou entre 65 e 82 anos.

As mulheres, aqui nomeadas como M1, M2, M3 até M13 tem apenas o ensino fundamental incompleto, visto que que dois não são alfabetizadas formalmente. Essas mulheres são separadas ou viúvas e uma tem namorado. Todas moram na cidade de Ivoti-RS, embora 
não tenham nascido no município. $\mathrm{O}$ homem, nomeado com $\mathrm{H}$, é nascido na cidade de Ivoti, tem cerca de 60 anos de idade, é casado e completou o ensino fundamental.

Intentou-se verificar os fatores de risco e de proteção presentes nas vidas dos idosos participantes dos atendimentos, a partir de seu próprio mundo, de seu olhar em uma perspectiva própria. Utilizou-se a técnica de história de vida que pressupõe que o comportamento humano pode ser compreendido por meio do olhar do próprio participante.

Os instrumentos de coleta de dados foram aplicados pela própria pesquisadora, individualmente, com cada um dos idosos participantes, em atendimentos individuais ou em grupo terapêutico, durante dois anos, constituindo-se do questionário de história de vida de Haigt (1979) e de uma representação gráfica em forma de mandala elaborada pelos próprios participantes.

Em conformidade com a resolução $n$. 196, de 10 de outubro de 1996, do Conselho Nacional de Saúde (CNS) e com as normas internas do Comitê de Ética em Pesquisa da Universidade Feevale, todos os participantes deste estudo assinaram o termo de consentimento livre e esclarecido.

\section{Apresentação dos resultados e discussão}

Buscando responder às questões apresentadas na introdução e considerando o objetivo geral de realizar um levantamento dos fatores de risco e de proteção evidenciados em idosos moradores da cidade de Ivoti-RS. Visando in- crementar as intervenções psicossociais para essa faixa etária, analisam-se e comentam-se os dados obtidos em dois momentos. Inicialmente, procede-se a apresentação dos dados obtidos mediante os atendimentos individuais ou em grupos realizados pela pesquisadora. Posteriormente, apresentam-se os dados obtidos da análise da mandala elaborada pelos participantes.

Os resultados iniciais indicam que 0 grupo pesquisado confirma dados também obtidos pelo projeto da Rede Fibra na cidade de Ivoti. Segundo o projeto, a maioria da população de idosos da cidade encontra-se entre 65 e 74 anos. $\mathrm{Na}$ população-alvo deste trabalho, oito dos 15 participantes encontravam-se nessa faixa etária.

A rede Fibra - Ivoti também identificou que em relação ao gênero a maioria era mulheres, casadas ou viúvas, da cor branca e aposentadas, alfabetizadas (ensino fundamental), moradoras de casa própria com renda de um a três salários mínimos. Participaram do estudo 14 mulheres e um homem, a maioria das mulheres com ensino fundamental e cor branca e quase todas proprietárias de suas casas com exceção das que moram no lar dentro do Hospital São José. Exceto uma das mulheres, as demais tinham renda de um a três salários mínimos.

Aspecto interessante a ser comentado é o fato de os idosos pesquisados serem, na maioria, do sexo feminino, o que comprova o processo de feminilização do envelhecimento. Em pesquisa realizada por Couto (2007) com 111 idosos, a autora também constatou esse fato. Das 111 pessoas pesquisadas, 92 eram mulheres 
e somente 19 eram homens. Os idosos participantes foram investigados sob a perspectiva de risco e, para tal, foram considerados os eventos de vida estressantes e sob a perspectiva de proteção foram considerados a rede de apoio social e o bem-estar psicológico já que esses fatores podem influenciar positiva ou negativamente a qualidade de vida na velhice. Com o objetivo de pontuar fatores de risco e de proteção presentes entre os idosos atendidos, foram elaboradas as figuras a seguir, partindo da história de vida de cada participante. Assim, podemos observar no Quadro 1 os fatores de risco mais citados pelos participantes.

Quadro 1 - Fatores de risco identificados no estudo

\begin{tabular}{|ll|}
\hline \multicolumn{1}{|c|}{ Fatores } & \multicolumn{1}{c|}{ Participantes } \\
\hline Ansiedade & $H, M 9, M 10$ \\
Culpa & $H, M 8, M 9$ \\
Trabalho árduo desde criança & $H, M 1, M 2, M 3, M 4, M 5, M 6, M 7, M 10$, \\
Doença & $H, M 1, M 2, M 3, M 4, M 5, M 6, M 9, M 10, M 11, M 12, M 13$ \\
Mora sozinha & $M 1, M 2, M 3$ \\
Família de origem desestruturada & $\mathrm{M} 2, M 3$ \\
Doença na família & $M 3, M 5, M 6, M 7, M 11$ \\
Auxilia no sustento da família & $M 4, M 5$ \\
Mudança de residência & $M 1, M 2, M 4, M 5, M 11, M 12, M 13$ \\
\hline
\end{tabular}

Fonte: elaborado pelas autoras.

Percebe-se que fatores que afetam a maioria dos idosos são: doença (12), trabalho na roça desde criança (9), mudança de residência (7), doença na família (5). Em pesquisa realizada por Hardy, Concocato e Gil (2002) com 154 idosos com idade superior a 70 anos, verificou-se que quatro tipos de eventos estressantes foram indicados como os mais frequentes: morte de um familiar ou amigo, doença de um familiar ou amigo, seu próprio adoecimento e evento não médico (vitimização e mudança de residência). Porém, um aspecto interessante a ser comentado é que os eventos estressantes podem ter consequências positivas em alguns casos. Por exemplo, no caso de M1 a mudança de residência, inicialmente, pode ter sido negativa, porém teve consequências positi- vas já que a paciente passou a cuidar de si, tanto que até engordou alguns quilos (era muito magra), faz psicoterapia e participa de grupos de idosos, atividade esta que não fazia antes da mudança de moradia.

$\mathrm{O}$ indicador de morar sozinha, para M1, constitui-se em fator de proteção da sua saúde mental já que o ex-marido a agredia psicologicamente. Porém, para M2 morar sozinha é difícil, pois é diabética, tem crises de hipoglicemia e, às vezes, não tem força para sair da cama. Para M3, que teve seu benefício negado, por um ano, pelo Instituto Nacional de Serviço Social (INSS), morar sozinha significa arcar com todas as despesas da casa, o que não é possível e, por isso, teve de pedir auxílio para a assistência social da cidade. 
A variedade de respostas, quanto a eventos com respostas positivas e/ou negativas, pode indicar diferentes graus de resiliência. Em relação a isso, Rutter (1987) refere que os fatores de proteção somente atuam, ou têm efeito, na presença de um fator de risco, ou seja, um fator de proteção é acionado ao ocorrer a exposição ao fator de risco. Nesse contexto, os mecanismos protetores reduzem as reações negativas decorrentes da exposição ao risco, pela manutenção da autoestima e autoeficácia e pela criação de oportunidades para reversão dos efeitos do estresse.

Outro fator citado por grande parte dos participantes é o fato de os indivíduos pesquisados trabalharem, desde jovens, na agricultura, o que já era esperado, pois a agricultura é um dos meios de sobrevivência da população de Ivoti.

No Quadro 2, observa-se os fatores de proteção percebidos pela pesquisadora durante os relatos dos idosos.

Quadro 2 - Fatores de proteção identificados no estudo

\begin{tabular}{|ll|}
\hline \multicolumn{1}{|c|}{ Fatores } & \multicolumn{1}{c|}{ Participantes } \\
\hline Mora com companheira/família & $\mathrm{H}, \mathrm{M} 4, \mathrm{M} 6, \mathrm{M} 7, \mathrm{M} 8, \mathrm{M} 10$ \\
Grupo psicoterapêutico/atendimento & $\mathrm{H}, \mathrm{M} 1, \mathrm{M} 2, \mathrm{M} 3, \mathrm{M} 4, \mathrm{M} 5, \mathrm{M} 6, \mathrm{M} 7, \mathrm{M} 8, \mathrm{M} 12, \mathrm{M} 13$ \\
psicoterapêutico & $\mathrm{M} 1, \mathrm{M} 2, \mathrm{M} 3, \mathrm{M} 4, \mathrm{M} 6, \mathrm{M} 7, \mathrm{M} 8$ \\
Grupos de idosos & $\mathrm{M} 1, \mathrm{M} 2, \mathrm{M} 3, \mathrm{M} 4, \mathrm{M} 5$ \\
Lazer & $\mathrm{H}, \mathrm{M} 1, \mathrm{M} 6, \mathrm{M} 7, \mathrm{M} 8, \mathrm{M} 12, \mathrm{M} 13$ \\
Boa relação familiar & $\mathrm{M} 1, \mathrm{M} 3, \mathrm{M} 4, \mathrm{M} 5, \mathrm{M} 6, \mathrm{M} 7, \mathrm{M} 12, \mathrm{M} 13$ \\
Religiosidade & $\mathrm{H}, \mathrm{M} 1, \mathrm{M} 2, \mathrm{M} 3, \mathrm{M} 5, \mathrm{M} 6, \mathrm{M} 7$ \\
Independência física & $\mathrm{H}, \mathrm{M} 1, \mathrm{M} 4, \mathrm{M} 5, \mathrm{M} 6, \mathrm{M} 12, \mathrm{M} 13$ \\
Família de origem bem estruturada & $\mathrm{H}, \mathrm{M} 2, \mathrm{M} 3$ \\
\hline Moradia própria & \\
\hline
\end{tabular}

Fonte: elaborado pelas autoras.

Analisando o Quadro 2, percebe-se que os fatores mais presentes são participar de grupo/atividade terapêutica (11), independência física (7), boa relação familiar (7), morar com familiar (6), religiosidade (8), família de origem bem estruturada (7). A possibilidade de participarem de grupos de apoio e/ou de atendimento psicológico acontece com 11 dos 14 participantes, ou seja, 78,5\% dos participantes deste estudo.

Couto (2007, p. 30) defende a ideia de que:
[...] o apoio social desempenha uma forte influência na saúde e no bem-estar dos indivíduos. De acordo com o Main Model a rede social influencia diretamente a saúde e o bem-estar. Pode promover o bem-estar ao fornecer fontes de autoestima, de vínculos afetivos, de aumento da competência, do reforço do senso de pertencimento, do fortalecimento da imagem pessoal e da promoção do senso de autoeficácia. Embora a rede social também possa criar dor e sofrimento, através de feedback negativo, há um relativo consenso de que é a ausência de rede social que pode gerar solidão e falta de sentido na vida. 
Pode-se compreender que a influência da estrutura e da função das redes sociais é um aspecto muito importante na velhice, especialmente devido ao fato de, nessa fase, haver a possibilidade de experienciar novos papéis sociais.

A independência e a saúde física, citados por $50 \%$ dos participantes, são aspectos também expressivos para que a resiliência se estabeleça. Apesar de diferentes dificuldades em relação à saúde, os idosos conseguem realizar suas atividades sem precisar de auxílio de outra pessoa.

Nos aspectos positivos ou de proteção, citados por Neri (2010) salienta-se uma maior longevidade, respostas adaptativas dos sistemas cardiovascular e imunológico, maiores recursos cognitivos (que incluem maior autoeficácia) e maior capacidade de manter o suporte social. Os indivíduos mais ativos, otimistas e bem-humorados têm, normalmente, maior longevidade e maior grau de capacidade para suportar intervenções cirúrgicas ou outras adversidades.

A dificuldade de aceitação da idade e, principalmente, a remoção indesejada para casa de idosos pode constituir-se em um forte fator de risco, fato ocorrido com M5, que precisou ser internada em outro espaço para atendimento psiquiátrico. Em relação às emoções negativas, como a hostilidade, a raiva, a ansiedade ou a depressão, Neri (2010) acredita que essas sejam susceptíveis de provocar maiores conflitos, menos apoio, excessos comportamentais, doenças, fraca resposta à frustração e várias fragilidades, 0 que se pode evidenciar com M5.
Os idosos, que em sua infância tiveram família estruturada, com pai e mãe presentes, que correspondem a $57,1 \%$ dos participantes, aparentam ter mais condições de enfrentar as adversidades já que são mais autônomos e conseguem enfrentar as dificuldades sem grandes comprometimentos.

Ao considerarmos o fator religião, $60 \%$ dos idosos o destacaram como aspecto essencial para sua sobrevivência. A participante M13, aos 84 anos, expressa isso claramente, quando afirma que a fé sempre serviu como guia em sua vida. M3 acredita que rezar ajuda a enfrentar a depressão; M1 confidencia que foi filha de Maria; ${ }^{2}$ M7 faz orações em casa e diz que acredita no apoio de Deus; M6 diz ter muita fé em Deus, o qual lhe dá força, $\mathrm{e}$ M3, diz estar viva porque tem fé.

No envelhecimento, o indivíduo atinge o ápice do seu desenvolvimento psíquico, e vários autores entendem que, a tarefa, nessa fase, é a de encontrar um significado para a vida, ou de aproximar-se da espiritualidade (GOLDSTEIN, 2003). Para Jung (1991), a religião é um instinto natural do ser humano, está na sua base arquetípica e manifesta-se, em todas as épocas da humanidade; a vivência religiosa facilita o processo de individuação, pois é um fator estruturante da psique, trazendo uma explicação vitalizadora para o ser humano. Desse modo, verifica-se que esses seis participantes, por meio da vivência religiosa, buscam uma solução interna que possibilite amenizar questões como a percepção da morte e as limitações impostas pela idade. 
Pensando em identificar os fatores de proteção, agora, sob a percepção dos próprios idosos, alguns dos participantes foram convidados a elaborar uma mandala com o que consideravam essencial em suas vidas. Nem todos os idosos participaram, já que alguns tinham comprometimentos físicos que dificultavam a execução da tarefa. As mandalas foram examinadas, de forma a se chegar aos dados necessários para elaboração do Gráfico 1.

\section{Gráfico 1 - Fatores de proteção}

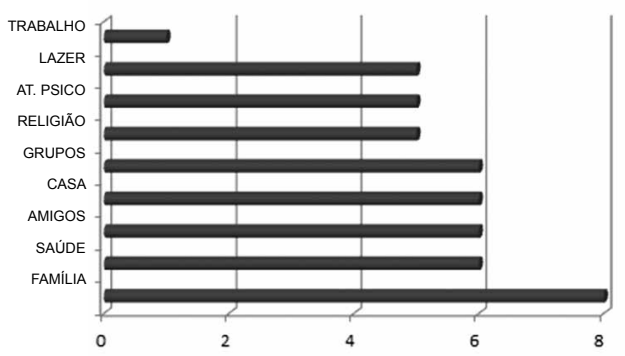

Fonte: elaborado pela autora.

Nos itens família, saúde, amigos, casa, grupos (entre esses os grupos de convivência e terapêuticos) encontram-se a maioria dos fatores considerados muito importantes pelos idosos. Torna-se evidente a importância de se ter um grupo de amigos, buscando manter contatos. O grupo de idosos pode tornar-se terapêutico, pois, por meio da participação nessas atividades, os indivíduos são convidados a elaborar uma nova construção que traz a compreensão de que a vida passa por escolhas e não por determinações do destino.

Santos (2006, p. 175) comenta a importância da família no processo de envelhecimento bem-sucedido ao afirmar que essa demonstra evitar a carência afetiva e a necessidade de contato. Além disso, o apoio familiar promove maior controle dos impulsos e das reações afetivo-emocionais do idoso.

Fatores como lazer, atendimento psicológico e religião são os aspectos citados em segundo plano. É inquestionável a relevância das redes de apoio para que os idosos envelheçam de forma bem-sucedi$\mathrm{da}$, visto que fatores de proteção vêm associados a essa rede social e ao seu papel de manutenção da saúde e do bem-estar do idoso. É por isso que investigações a respeito dos processos relacionados à rede social devem ser realizadas para gerar intervenções mais eficazes capazes de favorecer melhores condições de vida para os indivíduos. Além disso, laços sociais têm sido identificados como redutores de risco de depressão entre idosos e promotores de autoconfiança (COUTO, 2007).

\section{Considerações finais}

A resiliência pode ser descrita como um fator necessário para que o idoso restabeleça ou mantenha o seu nível de bem-estar mesmo frente a situações de risco. Devido à escassez de estudos que relacionam envelhecimento e resiliência, salienta-se a importância destes serem realizados, já que, no processo de envelhecimento deparamo-nos com diversos desafios físicos, sociais e psicológicos. Além disso, também é preciso que se mapeie, precisamente, o papel que os fatores de risco e de proteção envolvidos no processo de resiliência desempenham, bem como verificar de que modo esses interagem com o binômio saúde-doença. Ao estudarmos a resiliência em idosos, 
é possível reconhecer e potencializar recursos pessoais e interpessoais que protegem o desenvolvimento das pessoas. Assim, o presente estudo tem a possibilidade de tornar-se um instrumento para a compreensão e a promoção de um envelhecimento bem-sucedido, visando buscar novas estratégias de melhoria da qualidade de vida em idosos.

Em relação aos fatores de risco como aos de proteção, constatou-se que os relacionados à saúde e as relações interpessoais é que vão definir a qualidade de vida dos idosos. Esses aspectos já foram observados em outras pesquisas, porém o diferencial aqui encontrado é que os próprios participantes identifiquem esses aspectos como interferências relevantes.

As intervenções psicossociais, junto a idosos, devem considerar, em primeiro lugar, a força dos fatores de risco e de proteção, potencializados de acompanhamento sistemático que pode ser realizado por meio de atendimentos individuais e/ou grupais. Tais atendimentos necessitam ser sistemáticos, podendo contribuir para o autodesenvolvimento individual e grupal, bem como para reforçar o sistema de autoajuda e diminuir o isolamento. Esse trabalho deve ser desenvolvido com a comunidade e, por isso, a importância de recorrer-se a atividades interdisciplinares em que a Psicologia possa atuar, conjuntamente, com a família, com a assistência social, com a enfermagem e com a medicina.

Constatou-se que elementos da história de vida dos participantes estão relacionados à sua saúde atual. Dessa forma, sugere-se que propostas de intervenção com essa população levem em considera- ção forças ou recursos adaptativos potenciais (fatores de proteção), ou seja, que estes recursos sejam identificados e depois reforçados para que efetivamente atuem como fatores protetivos e possam conduzir ao desenvolvimento da resiliência.

Confirma-se que os fatores de proteção estão cada vez mais associados à rede de apoio social aos idosos. Por isso, mais pesquisas devem ser realizadas como forma de subsidiar intervenções mais eficazes para gerar melhores condições de vida. Constatou-se, também, que o processo de envelhecimento implica novas demandas que constituem desafios para governo e sociedade, embora seja necessária a compreensão de que a promoção da saúde depende de uma ação conjunta entre a sociedade, a academia e o governo.

\section{Risk and protection of elderly residents evidenced in Ivoti city-RS: psychosocial interventions hosocial intervention in the area of Gerontology}

\section{Abstract}

This article aims to survey the risk and protection factors demonstrated in elderly residents of Ivoti city (RS) as a way of improving psychosocial interventions for this age group. Fourteen patients participated in this study, thirteen women and one man. They attended group and individual sessions at a project developed by the Integrated Center of Psychology. Their ages ranged from 65 to 82 years. The theoretical model was based on integrating the human growth and development as a continuous process with matches with resilience, which can promote positive human potential. The methodology was qualitative, using an intervention research that allows through the life history reported by the elderly in 
individual and group sessions to perceive the risk and protective factors experienced by the participants. It was fond that the work of monitoring, listening and counseling the elderly may be one of the ways that the process of development of resilience can occur, thereby providing a successful aging. Psychosocial interventions need to be systematic so that they can contribute to individual and group self-development and to strengthen the system of self-help and reduce the isolation of the elderly.

Keyswords: Elderly. Risk factor. Protective factor. Resilience. Life history.

\section{Notas}

1 Trabalho realizado na cidade de Ivoti-RS na área de Psicogerontologia do projeto de extensão do Centro Integrado de Psicologia (CIP) da Universidade Feevale, em parceria com a Secretaria de Saúde e Assistência Social. Endereço para correspondência:Rua dos Andes, n. 286, São Leopoldo (RS), CEP: 93030-140.

2 Filha de Maria - grupo religioso dentro da Igreja Católica que congrega mulheres com objetivo de assistência social e de oração.

\section{Referências}

ASSIS, S., PESCE, R.; AVANCI, J. Resiliência: enfatizando a proteção de adolescentes. Porto Alegre: Artmed, 2006.

BALTES, P. B.; BALTES M. M. Sucessful aging: perspectives from behavioral sciences. Cambridge: Cambridge University, 1993.

BARROS, M. Velhice ou terceira idade? Estudos antropológicos sobre identidade, memória e política. Rio de Janeiro: Fundação Getúlio Vargas, 1998.

CARPENA, M. E.; KOLLER, S. Famílias de meninos em situação de rua na cidade de $\mathrm{Ca}$ xias do Sul: lócus de controle, situação atual de vida e expectativas para o futuro. Revista
Coletâneas e Saber, Caxias do Sul - UCS, v. 3, n. 3 p. 53-81, 1999.

CORDIOLI, A. V. Psicoterapias: abordagens atuais. 2. ed. Porto Alegre: Artes Médicas, 1998.

COUTO, M. C. Fatores de risco e de proteção na promoção de resiliência no envelhecimento. 2007. Dissertação (Mestrado em Psicologia) - Faculdade de Psicologia. Universidade Federal do Rio Grande do Sul (UFRGS), Porto Alegre, 2007.

ERIKSON, E. O ciclo de vida completo. Porto Alegre: Artmed, 1998.

FORTES, T.; PORTUGUEZ, M. E.; ARGIMON, I. A resiliência em idosos e sua relação com variáveis sociodemográficas e funções cognitivas. Estudos de Psicologia, Campinas-SP, v. 26, n. 4, p. 455-463, out./dez. 2009.

GOLDSTEIN, L. L. Desenvolvimento do adulto e religiosidade: uma questão de fé. In: Neri, A. Qualidade de vida e idade madura. Campinas: Papirus Editora, 2003. p. 83-108.

HARDY, S. E.; CONCOCATO, J.; GIL, T. M. Stressful life events among community-living older persons. Journal of General Internal Medicine, local de publicação, v. 17, n. 11, p. 841-847, nov. 2002.

HAIGT. Revisión de vida. 1979. Traducción y adaptación realizada por Serrano Selva, J. P. 2002. Disponível em: http://www.imsersomayores.csic.es. Acesso em: 28 fev. 2011.

JUNG, C. G. A dinâmica do inconsciente. Petrópolis: Vozes, 1984.

JUNG, C. G. A natureza da psique. Petrópolis: Vozes, 1991.

KOLLER, S. H. Resiliência e vulnerabilidade em crianças que trabalham e vivem na rua. Educar, Curitiba, n.15, p. 67-71, 1999.

NERI, A. L. Palavras-chave em gerontologia. Campinas: Alinea, 2005.

NERI, A. L. Desenvolvimento e envelhecimento: perspectivas biológicas, psicológicas e sociológicas. Campinas-SP: Papirus, 2001. 
NERI, A. L. Qualidade de vida na velhice e subjetividade. In: CONGRESSO INTERNACIONAL DE ENVELHECIMENTO HUMANO. Passo Fundo: Ed. Universidade de Passo Fundo, 2010.

NERI, A. L. Velhice saudável: fatores de risco e de proteção de natureza psicológica. In: Congresso Envelhecimento(s): cérebro, comportamento e emoções, 08 e 09 de outubro, Universidade dos Açores, 2010. Anais... Açores, 2010. Disponível em: http://www.pt.shvoong. com/.../2065286-velhice-saudável-factores-risco protecção/ Acesso em: 17 nov. 2010.

OSÓRIO, L. C. Grupoterapia hoje. Porto Alegre: Artes Médicas, 2007.

PESCE, R. et al. Risco e proteção: em busca do equilíbrio promotor de resiliência. Psicologia: Teoria e Pesquisa, Brasília, v. 20, n. 2, p. 135-143, ago. 2004.

PY, L.; PACHECO, J. L.; SÁ, J.; GOLDMAN, S. Tempo de envelhecer: percursos e dimensões psicossociais. Rio de janeiro: Nau, 2004.

REY, F. G. La investigación cualitativa en Psicologia. São Paulo: EDUC, 2000.

RUTTER, M. Psychosocial resilience and protective mechanisms. American Journal of Orthopsychiatric, Oxford. v. 57, n. 3, p. 316-331, July. 1987.

SANTOS, G. A. dos. A influência do estado conjugal no processo de envelhecimento bem-sucedido. In: PORTELLA, M.; PASQUALOTTI, A.; GAGLIETTI, M. Envelhecimento humano: saberes e fazeres. Passo Fundo: Ed. da Universidade de Passo Fundo, 2006. v. 1. p. 160-177.

SOUZA, O. Longevidade com criatividade: arteterapia com idosos. Belo Horizonte: Armazém de Ideias, 2005.

SZYMANSKI, H.; CURY, V., A pesquisa intervenção em psicologia da educação e clínica: pesquisa e prática psicológica. Estud. psicol., Natal, v. 9, n. 2, p. 345-353, maio/ ago. 2004.
ZIMERMAN, D. E. Fundamentos básicos das grupoterapias. Porto Alegre: Artmed, 2000.

ZIMERMAN, D. E; OSÓRIO, L. C. Como trabalhamos com grupos. Porto Alegre: Artmed, 1997. 